the inquiry it is necessary to define the term 'atmosphere'.

Both Wildt and Peek havo shown that beyond a depth of $100 \mathrm{~km}$. tho atmosphero of Jupiter must be compressed to the density of the liquid or solid state of the substances composing it. It is possible to conceive of this atmosphere as composed of highly condensed permanent gases, and at greater depths these gases may be solidified. The temperature of the surface of such an atmosphere would probably be in the neighbourhood of $150^{\circ} \mathrm{K} .\left(-123^{\circ} \mathrm{C}.\right)$, and from the dry adiabatic lapse-rate at the surface of Jupiter it is certain that the temperature must increase rapidly with the depth for the first few kilometres. When, however, the gas laws break down, it is probable that practically isothermal conditions prevail and the isotherm may be about $300^{\circ} \mathrm{K}$. Jeffreys' investigations suggest that $\mathfrak{a}$ thick layer composed of one of Bridgman's high-pressure modification of ice, probably ice vii, lies underneath, and Peek considers the case of an enormous berg, towering above the general lovel of the layer. Would the viscosity of the ice allow it to drift in longitude like the red spot?

Mr. Peek then develops a suggestion made by Wildt ${ }^{1}$ that the spot may be a solid body floating in an 'ocean of permanent gases', and proposes tho following tentative hypothesis: A solid body $A$, which is provisionally called ice, floats in a permanent gas $B$, provisionally called nitrogen. If the former is ice vii, it may be supposed that a small portion near the top would gradually change its phase from ice vii to ice vi, and, owing to the absorption of heat, the atmosphere above it would be cooled. The red spot is, it is thought, " $a$ manifestation at the visible surface of the thermal effects accompanying the change of phase".

Assuming further that the level at which the ice floats is subject to small variations, the radius of gyration about the axis of the planet will vary, and a simple calculation shows that a total range of $10 \mathrm{~km}$. would account for all the changes in velocity that the red spot has undergone during the period of investigation. While ice and nitrogen illustrate very readily the hypothesis, it is pointed out that the phase diagrams of other substances, such as hydrogen and helium, also suggest suitable conditions, and it is unnecessary to assume that ice and nitrogen are actually responsible for the phenomenon. It is hoped that the matter will be investigated more fully in the near future.

${ }^{1}$ Proc. Aner. Phil. Soc., 81, 2 (1939).

\title{
POSSIBILITIES OF ALTERNATING CURRENTS FOR LONG-DISTANCE TRANSMISSION
}

\begin{abstract}
TN the Electrical Review of October 20, H. Rissik shows that some of our early notions about the transmission of electric power must bo modified. In the past no difficulty was at first experienced in utilizing the line conductors to the full extent of their carrying capacity. Transmission distances were short and the power to be transmitted amounted to only a few thousand kilowatts. As time went on and transmission voltages and distances gradually increased, the view became common that any technical limitation to the amount of power that could be transmitted was to be looked for in the nature of the generating plant and transformers, rather than in those of the transmission line itself. It was seen that there was no longer a definite line voltage for a given power and distance giving the lowest trans. mission costs, which diminished as the voltage that could be used increased. Other characteristics of the electric plant had to be taken into account.

The special problems created by tho linking up of immense power networks operating at 132 and $154 \mathrm{kv}$. and in many cases at $220 \mathrm{kv}$., involving power interchange over Iong distances, first became acute in the United States, and thoy have also arisen in France, Germany and the U.S.S.R. To the pioneer work of American engineers we are indebted for our present knowledge of the essential factors which con. tribute to system instability. They have also developed methods of improving the stable operation of power systems. It is very creditable that individual electricity undertakings, operating on a very large scale, should havo deliberately subjected their power systems to major electrical disturbances in order to verify calculations based upon a new theory. This form of large-scale experimentation was on
\end{abstract}

several occasions undertaken in the United States, notably in 1928 on the $220 \mathrm{kv}$. system of the Southern California Edison Co. and again in 1930 on the $132 \mathrm{kv}$. system of the West Penn Electric Co.

As a result of the experience accumulated during the last ten years, it has becomo possible to investigate technically methods whereby the stability of superpower trunk lines may be raised to levels where economics once more becomes the decisive factor. It has been for a long time common practice to employ a synchronous condenser at the load end of a transmission line in order to maintain the terminal voltage common at all loads. In 1921 Baum showed that this principle could be extended to a long line divided into several sections and having synchronous condenser stations located at the points of section. Taken as a whole this transmission line acquires the electrical characteristics of its individual sections. As the result of the reactive power compensation effected by the intermediate condenser stations, the voltage at each point of section is maintained constant and equal to the transmission pressure.

Another system is the self-tuned line. To every frequency of alternating current there corresponds a wave-length, such that their product equals the velocity of propagation of the train of electric waves, just as in radio, television and carrier communication. For overhead lines, the velocity of propagation is approximately equal to the velocity of light, that is, about 180,000 miles per second, so that the wave. length of a 50 -cycle transmission line would be about 3,700 miles. Skilling showed in 1927 that if the transmission distance is just half the wave-length at the applied frequency, the line inductance and capacity cancel each other out and the line behaves 
virtually as if it possessed resistance only. Such a line constitutes a tuned circuit which resonates at tho frequency of the applied voltage. It would be difficult to realize this in practice as at the normal frequency of 50 the transmission distance would have to be 1,850 miles. This limitation of great length could be got over by the 'compensated line' system, where a series excitation scheme is artificially loaded with series capacitance. One successful application of this method was from a substation of the New York
Power and Light Corporation at $33 \mathrm{kv}$. installed in 1928. The chief disadvantages of using large static condensers is their expense and their liability to damage by over-voltage.

Another possible method would be to Ioad the line at intervals with shunt reactors, after the manner of the Pupin loading coils used in telephony, over underground cables. Such a dual compensated line would behave as if it possessed resistance only.

\section{OPERATION AND DESIGN OF TROLLEYBUSES}

\section{A} PAPER by G. F. Sinclair, of the London Passenger Transport Board, on the trolley. bus system was published by the Institution of Electrical Engineers on November 9. The trolleybus has been adjudged by the Ministry of Transport an electric vehicle, and its construction and operation are governed by the Ministry's regulations. These allow the vehicles to be built one ton heavier than other forms of road passenger vehicle. They can be designed with large seating capacities with accommodation up to seventy passengers.

The cost of maintaining a 70-seater trolloybus is not greater than that of the much smaller unit, the Diesel bus. On a mileage basis the capital charges on the vehicles, taken over a period of twelve years, assuming similar -seating capacities, show littlo difference when the two types are compared. The average energy consumption for trolleybuses operating on an intensive service is approximately $2 \cdot 75$ units per car mile, measured at the substation. The price of direct-current energy varies from $0.5 d$. to $0.8 d$. per unit. At the higher figure the cost per ton-mile is high compared with the Diesel bus, but at $0.5 \mathrm{~d}$. per unit the comparison is favourable to the trolleybus. For passenger services in densely populated areas, the vehicle with comparable costs, which can perform the cycle of starting and stopping to pick up and set down the greatest number of fare-paying passengers in the least time, will produce economies. The high acceleration of the trolleybus due to the overload capacity of its motor gives the facility for operating high schedule speeds. The ability to marshal vehicles in different areas is also a great convenience. In the everyday movement of the people on the road to and from their work, the use of nonstop vehicles plays little part. The travelling public have shown their appreciation of the comfort in travel, the fine riding qualities and quiet operation of these vehicles. The residential population and business people on tho routes served by trolleybuses have greatly benefited from their smooth and quiet running.

Among the many points interesting to all electricians touched on by Mr. Sinclair is the production of electric charges on trolleybuses, and the methods of suppressing the interference with radio transmission signals, whether of sound or vision broadcasts. In service, the electric charges may be produced by the friction of the tyres on the road surface, by the rise of potential due to the inductive kick from the contactor coils, possibly by the mutual induction from the currents in the transmission mains, or lastly when a leakage occurs from the power circuits to the body of the car. It has to be remembered that it is only in very special circumstances that these conditions can arise. In any event they present little inconvenience to the travelling public. Consider a rubber-tyred vehiclo with a metal or composite body ; the generation of a charge depends largely on the road surface. With dry clean granite sets, voltages up to 900 can be measured by an electrostatic voltmeter immediately after the vehicle comes to rest. If the roads are asphalt or tar-macadam, only zero readings will be obtained. When the circuits of the electrical equipment are broken, the inductive charges may give voltages up to 300 . Neither of these types of charges necessitates special precautions, as the frequency of loading or unloading passengers provents high static charges from being built up. The use of 'low resistance' tyres, of about 2,000 ohms measured from the tread to the wheel rim, provides satisfactorily for earthing these charges.

It is the possibility of electrical leakage from the 600 -volt circuits which has to be guarded againstthe vehicle being in reality unearthed. The Ministry of 'Transport regulations require a daily test of the insulation of each trolleybus. The test is carried out after the vehicle has completed each day's service. Testing apparatus is located at the entrance of the depots. This enables the test to be carried out with the trolleybus in the condition in which it has been operating, an especially important point in wet or snowy weather, as the insulation resistance varies largely with the climatic conditions. For convenience in testing, the frames of the individual 600 -volt units are connected by means of cables to a common testing receptacle, which is mounted at the back of the trolleybus underneath tho platform. The nightly test is between the conductors and the body or chassis, the secondary insulation being short. circuited. Every fourteen days, each high-voltage circuit is tested individually, including all insulation whether primary or secondary. The insulation of the platform consists of a rubber mat secured to the floor boarding by an adhesive. The handrails have an insulated covering and are provided with secondary insulation, the combined arrangement giving insulation readings of 'infinity'.

The British Standards Institution has recently published a specification setting out the three methods used for reducing the electrical interference with radio broadcasting, etc., generated by the trolleybus equipment. The results of large-scale experiments carried out in London for preventing interference by trolley. buses are described.

On a fleet of more than 1,600 trolleybuses in London, the use of carbon 'shoes' to collect the current from the overhead wires is general. The success of the carbon collectors is due largely to the lubrication of the conductors. 